\title{
Interprofessional Education in U.S. Dental Hygiene Programs: Program Director Responses Before and After Introduction of CODA Standard 2-15
}

\begin{abstract}
Danielle Furgeson, Marita R. Inglehart
Abstract: A 2014 survey found that dental hygiene program directors perceived interprofessional education (IPE) as a priority for themselves and the dental hygiene profession in the U.S. The aim of this study was to explore whether IPE collaborations in dental hygiene programs and program directors' attitudes changed from 2014 to 2017 since the Commission on Dental Accreditation (CODA) Standard 2-15 on IPE was introduced in August 2016. In May 2017, directors of all 325 U.S. dental hygiene programs were invited to participate in a web-based survey. A total of 117 directors responded, for a $38 \%$ response rate, and their responses were then compared with the responses in 2014 (that survey had a 33\% response rate). The results showed that, while the percentage of responding dental hygiene programs with a nursing program on campus had decreased ( $90 \%$ to $80 \%$; $<<0.022)$, the likelihood of having other health care-related programs on campus did not change. In 2017 as compared to 2014, the programs were still most likely to collaborate with nursing (50\% vs. 46\%) and other allied health professions (44\% vs. 56\%) and in intraprofessional education with dental assisting programs (41\% vs. 41\%). IPE was still most likely to occur in volunteer activities (68\% vs. $73 \%$ ), basic science courses (65\% vs. $60 \%)$, and communications training (63\% vs. $63 \%)$. In 2017 , program directors rated IPE as less challenging for programs to manage than in 2014 (on five-point scale with 1=not at all challenging: 3.31 vs. 3.62 ; $\mathrm{p}=0.022$ ). However, the responding directors did not view IPE as being as important to the profession in 2017 as the respondents reported in 2014 (3.29 vs. 3.88; $<<0.001$ ). The majority in 2017 agreed/strongly agreed that Standard 2-15 will improve the profile of dental hygiene as part of the health care team (77\%) and contribute to integrating dental hygiene into interprofessional care (IPC) teams (78\%). Overall, this study found that the introduction of an explicit IPE dental hygiene CODA standard in 2016 had already resulted in changes after only one year. However, the responding program directors' lower agreement with statements concerning their graduates' IPC-related competence deserves further attention.
\end{abstract}

Danielle Furgeson, RDH, MS, DHSc, is Director, Graduate Dental Hygiene Program, and Clinical Assistant Professor, Department of Periodontics and Oral Medicine, School of Dentistry, University of Michigan; and Marita R. Inglehart, Dr phil habil, is Professor, Department of Periodontics and Oral Medicine, School of Dentistry, and Adjunct Professor, Department of Psychology, College of Literature, Science, and Arts, University of Michigan. Direct correspondence to Dr. Danielle Furgeson, Department of Periodontics and Oral Medicine, University of Michigan School of Dentistry, 1011 N. University Street, Ann Arbor, MI 48109-1078; 734-764-0033; furgeson@umich.edu.

Keywords: dental hygiene, dental hygiene education, dental hygiene programs, interprofessional education, interprofessional care, allied dental education

Submitted for publication 2/21/18; accepted 7/5/18 doi: 10.21815/JDE.019.002

A ddressing patients' complex health care needs optimally can be challenging for individual providers. Increasing numbers of patients have multiple chronic conditions, requiring well-coordinated interprofessional care (IPC) to achieve optimal health outcomes. ${ }^{1}$ The IPC triple aim was developed to improve the delivery of health care in an increasingly complicated system, improve patients' health outcomes, and reduce costs., ${ }^{2,3}$ The realization that patient care is complex and requires the coordinated efforts of multiple contributors has created a paradigm shift that was well described in 2010 in a World Health Organization (WHO) report that highlighted the importance of IPC as a means to provide improved health care services and achieve better outcomes. ${ }^{4}$ Since then, efforts to institute IPC have consistently increased. These shared, teambased approaches have been shown to reduce cost and errors, while improving quality of care and health outcomes. ${ }^{5,6}$

In 2015, the Institute of Medicine highlighted the fact that providers were rarely educated together 
nor did they learn the skills and norms for IPC and team-based approaches. ${ }^{7,8}$ Team-based care involves the patient and providers from at least two professions or disciplines for coordinated patient care and outcomes, ${ }^{1,9}$ while IPC has been defined as the optimal provision of patient care via the contribution of areas of specialization and the use of evidence-based decision making. ${ }^{10}$ Health professions education must evolve by shifting from "siloed" learning to interprofessional education (IPE) to provide a strong foundation for IPC in clinical practice. ${ }^{7,11}$

This change in the health care delivery system includes the provision of oral health care. The types of practice settings in which allied dental health care providers are practicing is expanding beyond the traditional private practice where there may be little or no IPC..$^{12}$ Accordingly, dental hygiene programs have to accept the responsibility of including IPE in their curricula, as the collaborative care settings in which dental hygienists practice will continue to change for the foreseeable future. ${ }^{13,14}$ Primary care settings where dental hygienists are the only preventive oral health team members present are also likely to increase over the next several decades. ${ }^{13}$

To fill these roles competently, current and future dental hygienists must be educated with a new skill set. ${ }^{13}$ IPE has been described as the means of creating a workforce able to engage in health care delivery via IPC. ${ }^{11}$ According to the WHO, IPE occurs when students from two or more professions learn about, from, and with each other to enable effective collaboration and improve health outcomes. ${ }^{4}$ The American Dental Education Association (ADEA) IPE Taskforce added that IPE occurs when students from two or more health professions learn together during all or part of their professional training. ${ }^{15}$ The alignment of health professions education with the expected practice setting must include students' learning and working together as teams. ${ }^{7}$ IPE has been found to improve patient outcomes and students' attitudes towards team-based IPC. ${ }^{7,16}$ Dental hygiene educators must continue to assess how the delivery of oral health is changing and how their own attitudes must be changed in order to maximize contribution to IPC teams. ${ }^{17}$

Oral health is an integral part of overall health and patient care. ${ }^{3,13}$ Dental hygiene educators must therefore prepare dental hygienists for their role in the current and future health care delivery system. Dental hygiene programs are strategically positioned to collaborate with other allied health professions to provide oral health care in the primary care setting. ${ }^{18}$ Although dental hygienists are increasingly practicing IPC in community-based and other nontraditional settings as a result of evolving scopes of practice, ${ }^{19}$ dental hygiene educational programs continue to focus almost solely on preparing students for private practice. ${ }^{3,13}$ While students' attainment of clinical competence is foundational for dental hygiene education, IPE is quickly becoming the standard across all disciplines. Dental hygiene curricula must keep pace with the changing paradigm to ensure dental hygienists will be valuable contributors to IPC teams by including clinical IPE with other disciplines. ${ }^{13}$

In consideration of this situation, it was not surprising that the Commission on Dental Accreditation (CODA) Accreditation Standards for Dental Hygiene Education Programs revised Standard 2-15 in August 2016 to explicitly include IPE. This standard now states that "Graduates must be competent in communicating and collaborating with other members of the health care team to support comprehensive patient care." ${ }^{20}$ Furgeson et al. surveyed dental hygiene program directors regarding their IPE-related efforts and attitudes in 2014, when only implicit references to IPE were made in the CODA standards, ${ }^{21}$ but no prior study has assessed whether educational efforts and attitudes changed as a consequence of the CODA standard changes in August 2016.

In this context, it would also be beneficial to explore how the implementation of IPE challenges dental hygiene programs. Potential difficulties such as coordinating schedules, identifying the appropriate location and times in curricula, acquiring adequate institutional support, and overcoming cultural challenges of individual disciplines must all be carefully considered..$^{21}$ Dental hygiene education is most frequently delivered in two-year programs, with few opportunities for intra- or interprofessional education due to already crowded curricula. ${ }^{13,14}$ Gaining a better understanding of programs' efforts to manage these challenges in meeting the new IPE standard can therefore be helpful. The aim of this study was therefore to explore whether IPE collaborations in dental hygiene programs and program directors' attitudes changed from 2014 to 2017 since CODA Standard 2-15 on IPE was introduced in August 2016. Specifically, we compared newly collected survey data with that from 2014 to assess how dental hygiene programs engaged in IPE after introduction of Standard 2-15, the challenges they encountered, and their directors' perceptions of the value of IPE. 


\section{Methods}

This study was determined to be exempt from Institutional Review Board (IRB) oversight by the Health Sciences and Behavioral Sciences IRB at the University of Michigan (HUM\#00083956). Participants in both the 2014 and the 2017 surveys were directors of U.S. dental hygiene education programs.

In 2017, the email addresses of directors of all 325 entry-level dental hygiene programs were obtained from the dental hygiene education program page on the American Dental Hygienists' Association (ADHA) website. Qualtrics was used for this webbased survey since it can use an Excel spreadsheet with email addresses and send out one email to all addressees at the same time. The first recruitment email to the program directors was sent on May 31, 2017, and two follow-up emails were sent on June 7, 2017, and June 22, 2017. The emails informed the program directors about the research and asked them to access the web-based, anonymous survey via a link provided in the message. The recruitment emails were sent to all 325 program directors; 14 of these emails were returned as undeliverable.

In the survey conducted in 2014, a list of email addresses of the program directors was obtained from the ADHA and used to send out single recruitment emails because the web-based survey program used at that time could not incorporate the Excel spreadsheet of email addresses as was done in 2017. Sending the emails therefore took several days. The first recruitment email was sent to 305 valid email addresses in February 2014, and a follow-up email was sent in April 2014.

The 2014 survey was a revised version of the survey used by the ADEA Team Study Group on Interprofessional Education to investigate IPE activities in U.S. and Canadian dental schools..$^{15}$ Permission to adapt this survey for use with U.S. dental hygiene programs was obtained from Dr. Allan J. Formicola, the head of the ADEA Study Group. The investigators of the 2014 study made two revisions to the original dental school survey. They changed the program characteristics questions to be appropriate for dental hygiene program directors, and they replaced the IPE-related predoctoral dental CODA standard numbers in the dental school survey with the dental hygiene CODA standards that were indirectly relevant to IPE. ${ }^{21}$ In the 2017 study, we made one change to the dental hygiene survey used in 2014. The fact that an explicit reference to IPE had been added to CODA Standard 2-15 of the dental hygiene standard $s^{20}$ required changing the referenced accreditation standard in the 2017 survey.

The 2014 and 2017 dental hygiene surveys both included the same questions about program characteristics such as the program's educational setting, type of degree the program granted, annual number of graduates, and program length. The second part of both surveys asked about potential IPE collaborations between the programs and other disciplines on their campus and about actual IPE programs. In addition, some questions asked in which specific IPE activities the programs were engaged, such as joint volunteer service, joint clinical activities, or joint basic science courses. The third part of both surveys asked how these IPE activities were related to the CODA standards. In the 2017 survey, Standard 2-15 was used as the reference point. ${ }^{20}$ These questions asked which IPE activities were included in the curriculum, the importance the directors ascribed to IPE activities, and other IPE-related questions. The last part of the survey asked about challenges encountered in trying to engage in IPE activities and how the changes to Standard 2-15 had affected the program.

The data were downloaded from the Qualtrics website as SPSS data files (Version 22; IBM Corp., Armonk, NY, USA). Descriptive statistics such as frequencies, percentages, means, and standard deviations were computed to provide an overview of the closed-ended answers. Independent sample t-tests were used to determine if average responses of the program directors in 2014 and 2017 differed significantly. Chi-squared tests were used to determine if the frequencies of the directors' categorical responses in 2014 and 2017 differed significantly. A p-value of $<0.05$ was accepted as the level of significance.

\section{Results}

In 2014, data were collected from 102 program directors, for a response rate of $33 \%{ }^{21}$ Of the 325 program directors invited to participate in the 2017 survey, 117 responses were received, for a response rate of $38 \%$.

There was no significant difference between 2014 and 2017 in the educational settings where responding programs were located (Table 1). Approximately $50 \%$ were located in both years at a community or junior college. The type of degrees awarded also did not differ significantly for those two years. While there was no difference in the average number of students who graduated per year, there was a significant difference in average program length with programs being longer in 2017 than in 2014. 
Table 1. Characteristics of responding dental hygiene programs in 2014 and 2017

\begin{tabular}{|c|c|c|c|c|c|}
\hline \multirow[b]{2}{*}{ Characteristic } & \multicolumn{2}{|c|}{$2014(\mathrm{~N}=102)$} & \multicolumn{2}{|c|}{$2017(\mathrm{~N}=117)$} & \multirow[b]{2}{*}{ p-value } \\
\hline & Number & $\%$ & Number & $\%$ & \\
\hline \multicolumn{6}{|l|}{ Location of program } \\
\hline Community or junior college & 50 & $49 \%$ & 60 & $51 \%$ & n.s \\
\hline University or 4-year college & 30 & $29 \%$ & 28 & $24 \%$ & \\
\hline Dental school & 14 & $14 \%$ & 12 & $10 \%$ & \\
\hline Technical college & 6 & $6 \%$ & 13 & $11 \%$ & \\
\hline Other & 2 & $2 \%$ & 4 & $3 \%$ & \\
\hline \multicolumn{6}{|l|}{ Degree granted* } \\
\hline Associate degree & 81 & $79 \%$ & 88 & $75 \%$ & n.s \\
\hline Baccalaureate degree & 30 & $29 \%$ & 40 & $34 \%$ & \\
\hline Diploma/certificate & 3 & $3 \%$ & 1 & $1 \%$ & \\
\hline Master's degree & 3 & $3 \%$ & 9 & $8 \%$ & \\
\hline \multicolumn{6}{|l|}{ Program has } \\
\hline Undergraduate program only & 93 & $91 \%$ & 109 & $93 \%$ & n.s. \\
\hline \multirow[t]{2}{*}{ Undergraduate and graduate programs } & 9 & $9 \%$ & 8 & $7 \%$ & \\
\hline & Mean & SD Range & Mean & SD & \\
\hline Number of students who graduate per year & 24.92 & $\begin{array}{c}10.515 \\
10-60\end{array}$ & 26.99 & 19.954 & n.s. \\
\hline Program length in number of months & 25.80 & $\begin{array}{c}6.04 \\
18-48\end{array}$ & 28.02 & 8.69 & 0.029 \\
\hline n.s.=non-significant & & & & & \\
\hline *Respondents could select all that applied. & & & & & \\
\hline
\end{tabular}

Overall, there were slightly fewer other health professions programs located on the dental hygiene programs' campuses in 2017 compared to 2014 (Table 2). However, the average numbers of collaborations were not significantly different between the two years. In both years, the responding dental hygiene programs were most likely to have collaborated with nursing schools, followed by other allied health programs and (in intraprofessional education) dental assisting programs. Most of the responding programs reported having a nursing school as well as other allied health programs on campus. When asked with which programs the dental hygiene programs were most likely to collaborate in IPE efforts, nursing schools were named most frequently in 2014, and other allied health programs were most frequently named in 2017. Approximately four out of ten dental hygiene program directors reported that they collaborated with dental assisting programs in intraprofessional efforts in both years.

When the program directors were asked about which activities involved interactions between students from different disciplines, the responses were rather similar in the two years (Table 3 ). The most frequently named responses were volunteer activities (2014: 68\% vs. 2017: 73\%), followed by basic science-related activities (2014: 65\% vs. 2017: 60\%).
The majority of responding programs also mentioned communication training $(63 \%)$ and behavioral science courses $(59 \%)$ at both time points. Servicelearning projects were also frequently reported (2014: 50\% vs. 2017: 54\%).

Table 4 provides an overview of challenges related to IPE reported by respondents in the two years. In 2014, the respondents on average described IPE as being more challenging for their program than in 2017 (on scale from 1=not at all to $5=$ very challenging: 2014 mean 3.62 vs. 2017 mean 3.31; $\mathrm{p}=0.022$ ). When asked if they encountered specific IPE-related challenges, the most frequently reported challenges in 2014 and 2017 were schedule coordination (2014: 92\% vs. 2017: 89\%) and curriculum overload (2014: $76 \%$ vs. 2017: 68\%).

The survey also asked program directors how much IPE was one of their personal, their academic institutions', and the dental hygiene profession's top five priorities. While the average responses concerning the program directors' and academic institutions' priorities did not differ between 2014 and 2017, there was a significantly lower response in 2017 compared to 2014 regarding whether IPE was one of the top five priorities for the dental hygiene profession in the U.S. (2014: mean 3.88 vs. 2017: mean 3.29; $\mathrm{p}<0.001$ ) (Table 5). 
Table 2. Health professions programs at dental hygiene programs' institutions and those with which the programs collaborate for intra- and interprofessional activities, by percentage of total respondents in $2014(\mathrm{~N}=102)$ and 2017 ( N=117)

\begin{tabular}{|c|c|c|c|c|c|}
\hline Program & Year & Yes at Institution & p-value & Yes for Collaboration & p-value \\
\hline Dental school & $\begin{array}{l}2014 \\
2017\end{array}$ & $\begin{array}{l}20 \% \\
14 \%\end{array}$ & 0.159 & $\begin{array}{l}28 \% \\
21 \%\end{array}$ & 0.146 \\
\hline Dental specialty graduate program & $\begin{array}{l}2014 \\
2017\end{array}$ & $\begin{array}{l}18 \% \\
14 \%\end{array}$ & 0.266 & $\begin{array}{l}18 \% \\
13 \%\end{array}$ & 0.210 \\
\hline Dental therapy program & $\begin{array}{l}2014 \\
2017\end{array}$ & $\begin{array}{c}0 \\
1 \%\end{array}$ & 0.534 & $\begin{array}{l}2 \% \\
1 \%\end{array}$ & 0.448 \\
\hline Dental assisting program & $\begin{array}{l}2014 \\
2017\end{array}$ & $\begin{array}{l}41 \% \\
44 \%\end{array}$ & 0.412 & $\begin{array}{l}41 \% \\
41 \%\end{array}$ & 0.546 \\
\hline Medical school & $\begin{array}{l}2014 \\
2017\end{array}$ & $\begin{array}{l}21 \% \\
14 \%\end{array}$ & 0.119 & $\begin{array}{l}11 \% \\
12 \%\end{array}$ & 0.477 \\
\hline Physician assistant program & $\begin{array}{l}2014 \\
2017\end{array}$ & $\begin{array}{l}20 \% \\
18 \%\end{array}$ & 0.443 & $\begin{array}{c}8 \% \\
10 \%\end{array}$ & 0.353 \\
\hline Nursing school & $\begin{array}{l}2014 \\
2017\end{array}$ & $\begin{array}{l}90 \% \\
80 \%\end{array}$ & 0.022 & $\begin{array}{l}50 \% \\
46 \%\end{array}$ & 0.333 \\
\hline Pharmacy program & $\begin{array}{l}2014 \\
2017\end{array}$ & $\begin{array}{l}25 \% \\
21 \%\end{array}$ & 0.347 & $\begin{array}{c}10 \% \\
9 \%\end{array}$ & 0.550 \\
\hline Physical therapy program & $\begin{array}{l}2014 \\
2017\end{array}$ & $\begin{array}{l}32 \% \\
25 \%\end{array}$ & 0.138 & $\begin{array}{c}7 \% \\
13 \%\end{array}$ & 0.107 \\
\hline Other allied health program & $\begin{array}{l}2014 \\
2017\end{array}$ & $\begin{array}{l}85 \% \\
85 \%\end{array}$ & 0.521 & $\begin{array}{l}44 \% \\
56 \%\end{array}$ & 0.060 \\
\hline Psychology department & $\begin{array}{l}2014 \\
2017\end{array}$ & $\begin{array}{l}61 \% \\
52 \%\end{array}$ & 0.125 & $\begin{array}{l}10 \% \\
3 \%\end{array}$ & 0.049 \\
\hline Social work program & $\begin{array}{l}2014 \\
2017\end{array}$ & $\begin{array}{l}44 \% \\
41 \%\end{array}$ & 0.373 & $\begin{array}{l}10 \% \\
7 \%\end{array}$ & 0.290 \\
\hline Other programs & $\begin{array}{l}2014 \\
2017\end{array}$ & $\begin{array}{l}28 \% \\
24 \%\end{array}$ & 0.273 & $\begin{array}{l}18 \% \\
18 \%\end{array}$ & 0.548 \\
\hline Sum of programs: Mean/SD & $\begin{array}{l}2014 \\
2017\end{array}$ & $\begin{array}{l}5.11 / 2.70 \\
4.31 / 2.47\end{array}$ & 0.023 & $\begin{array}{l}2.75 / 2.17 \\
2.40 / 2.06\end{array}$ & 0.231 \\
\hline
\end{tabular}

Table 3. Comparison of types of activities involving students from different disciplines, by percentage of total respondents in $2014(\mathrm{~N}=102)$ and $2017(\mathrm{~N}=117)$

\begin{tabular}{lccc} 
Activity & Year & $\%$ Yes & p-value \\
\hline Volunteer activities & 2014 & $68 \%$ & 0.261 \\
& 2017 & $73 \%$ & \\
Basic science course & 2014 & $65 \%$ & 0.266 \\
Communication training & 2017 & $60 \%$ & \\
& 2014 & $63 \%$ & 0.531 \\
Behavioral science courses & 2017 & $63 \%$ & \\
& 2014 & $59 \%$ & 0.328 \\
Service-learning projects & 2017 & $59 \%$ & \\
& 2014 & $50 \%$ & 0.306 \\
Community-based clinical & 2017 & $54 \%$ & \\
education & 2014 & $48 \%$ & 0.104 \\
Clinical activities & 2017 & $39 \%$ & \\
& 2014 & $43 \%$ & 0.335 \\
Standardized patient programs & 2017 & $47 \%$ & \\
& 2014 & $25 \%$ & 0.329 \\
Ethics classes & 2017 & $21 \%$ & \\
Sum of activities: Mean/SD & 2014 & $8 \%$ & 0.113 \\
& 2017 & $14 \%$ & \\
& 2014 & $4.27 / 2.13$ & 0.783 \\
& 2017 & $4.19 / 2.18$ &
\end{tabular}

Table 4. Dental hygiene program directors' perceptions of challenges with interprofessional education (IPE)

\begin{tabular}{|c|c|c|c|}
\hline Item & Year & $\begin{array}{l}\text { Mean/ } \\
\% \text { Yes }\end{array}$ & p-value \\
\hline $\begin{array}{l}\text { How challenging is IPE for your } \\
\text { program overall? (Mean) }\end{array}$ & $\begin{array}{l}2014 \\
2017\end{array}$ & $\begin{array}{l}3.62 \\
3.31\end{array}$ & 0.022 \\
\hline \multicolumn{4}{|c|}{ IPE challenges encountered (\% Yes) } \\
\hline Schedule coordination & $\begin{array}{l}2014 \\
2017\end{array}$ & $\begin{array}{l}92 \% \\
89 \%\end{array}$ & 0.413 \\
\hline Curriculum overload & $\begin{array}{l}2014 \\
2017\end{array}$ & $\begin{array}{l}76 \% \\
68 \%\end{array}$ & 0.244 \\
\hline Calibrated faculty & $\begin{array}{l}2014 \\
2017\end{array}$ & $\begin{array}{l}48 \% \\
38 \%\end{array}$ & 0.119 \\
\hline $\begin{array}{l}\text { Opportunities for meaningful } \\
\text { student interactions }\end{array}$ & $\begin{array}{l}2014 \\
2017\end{array}$ & $\begin{array}{l}42 \% \\
41 \%\end{array}$ & 0.865 \\
\hline Room space & $\begin{array}{l}2014 \\
2017\end{array}$ & $\begin{array}{l}33 \% \\
25 \%\end{array}$ & 0.163 \\
\hline Evaluating outcomes & $\begin{array}{l}2014 \\
2017\end{array}$ & $\begin{array}{l}32 \% \\
27 \%\end{array}$ & 0.514 \\
\hline $\begin{array}{l}\text { Partnership opportunities in } \\
\text { home institution }\end{array}$ & $\begin{array}{l}2014 \\
2017\end{array}$ & $\begin{array}{l}26 \% \\
22 \%\end{array}$ & 0.571 \\
\hline Support from administration & $\begin{array}{l}2014 \\
2017\end{array}$ & $\begin{array}{l}16 \% \\
9 \%\end{array}$ & 0.103 \\
\hline Educational resources & $\begin{array}{l}2014 \\
2017\end{array}$ & $\begin{array}{l}14 \% \\
16 \%\end{array}$ & 0.604 \\
\hline Sum of challenges: Mean/SD & $\begin{array}{l}2014 \\
2017\end{array}$ & $\begin{array}{l}3.77 / 1.757 \\
3.35 / 1.876\end{array}$ & 0.087 \\
\hline
\end{tabular}

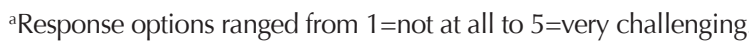


The program directors were also asked to respond to four statements concerning their graduates' IPE-related competencies. The first competency about "working with individuals of other professions to maintain a climate of mutual respect and shared values" was on average rated as being less important in 2017 than in 2014 (2014: 4.59 vs. 2017: 4.34; $\mathrm{p}<0.05$ ) (Table 5). This same pattern of responses was found concerning the directors' agreement with the other three statements. In 2014, the respondents agreed less strongly that their graduates must be competent concerning "using the knowledge of one's own role and those of other professionals to appropriately assess and address the health care needs of patients and populations served" (statement 2, 2014: 4.56 vs. 2017: 4.24; $\mathrm{p}<0.01$ ); “communicating with patients, families, communities, and other health professionals in a responsive and responsible manner that supports a team approach to the maintenance of health and treatment of disease" (statement 3, 2014: 4.65 vs. $2017: 4.32 ; \mathrm{p}<0.01$ ); and being able to "apply relationship-building values and principles of team dynamics to perform effectively in team roles to plan and deliver patient-/population-centered care that is safe, timely, efficient, effective, and equitable" (statement 4, 2014: 4.55 vs. 2017: 4.26; $\mathrm{p}<0.05$ ).

Table 6 provides an overview of the responses to questions about the explicit introduction of IPC into the dental hygiene accreditation standards. When asked whether their programs were compliant with the revised standard, $3 \%$ of respondents disagreed strongly and $9 \%$ disagreed, while $26 \%$ agreed and $36 \%$ agreed strongly that their program was compliant with this standard. Concerning specific attitudes related to this standard, 77\% agreed/agreed strongly that Standard 2-15 will improve the profile of dental hygienists as members of the health care team, 78\% that the standard would contribute to integrating dental hygiene into IPC teams, $67 \%$ that it will improve patient care, and $64 \%$ that it will improve dental hygiene education efforts. While $65 \%$ considered revision of the standard as a timely action, $60 \%$ reported that it would be a challenge for their program to revise the curriculum and $48 \%$ that doing so would require additional resources. Curriculum overload was considered by $47 \%$ as a barrier, and $13 \%$ agreed/ strongly agreed that the addition to Standard 2-15 was an unnecessary action.

Table 5. Comparison of responses on dental hygiene program directors' interprofessional education (IPE) values, by percentage of total respondents in $2014(\mathrm{~N}=102)$ and $2017(\mathrm{~N}=117)$

\begin{tabular}{|c|c|c|c|c|c|c|c|c|}
\hline Item & Year & 1 & 2 & 3 & 4 & 5 & Mean & p-value \\
\hline \multicolumn{9}{|l|}{ IPE is one of top five priorities for ${ }^{a}$} \\
\hline Me as a dental hygiene program director. & $\begin{array}{l}2014 \\
2017\end{array}$ & $\begin{array}{l}2 \% \\
2 \%\end{array}$ & $\begin{array}{c}10 \% \\
8 \%\end{array}$ & $\begin{array}{l}29 \% \\
30 \%\end{array}$ & $\begin{array}{l}34 \% \\
31 \%\end{array}$ & $\begin{array}{l}24 \% \\
30 \%\end{array}$ & $\begin{array}{l}3.68 \\
3.79\end{array}$ & 0.444 \\
\hline My academic institution. & $\begin{array}{l}2014 \\
2017\end{array}$ & $\begin{array}{l}8 \% \\
7 \%\end{array}$ & $\begin{array}{l}26 \% \\
19 \%\end{array}$ & $\begin{array}{l}26 \% \\
31 \%\end{array}$ & $\begin{array}{l}22 \% \\
26 \%\end{array}$ & $\begin{array}{l}18 \% \\
18 \%\end{array}$ & $\begin{array}{l}3.15 \\
3.28\end{array}$ & 0.410 \\
\hline The dental hygiene profession in the U.S. & $\begin{array}{l}2014 \\
2017\end{array}$ & $\begin{array}{l}1 \% \\
8 \%\end{array}$ & $\begin{array}{c}8 \% \\
19 \%\end{array}$ & $\begin{array}{l}26 \% \\
33 \%\end{array}$ & $\begin{array}{l}32 \% \\
17 \%\end{array}$ & $\begin{array}{l}33 \% \\
24 \%\end{array}$ & $\begin{array}{l}3.88 \\
3.29\end{array}$ & $<0.001$ \\
\hline \multicolumn{9}{|l|}{ Graduates must be competent to ${ }^{\mathrm{b}}$} \\
\hline $\begin{array}{l}\text { Work with individuals of other professions } \\
\text { to maintain a climate of mutual respect } \\
\text { and shared values. }\end{array}$ & $\begin{array}{l}2014 \\
2017\end{array}$ & $\begin{array}{c}0 \\
2 \%\end{array}$ & $\begin{array}{l}1 \% \\
7 \%\end{array}$ & $\begin{array}{c}10 \% \\
8 \%\end{array}$ & $\begin{array}{l}16 \% \\
23 \%\end{array}$ & $\begin{array}{l}72 \% \\
60 \%\end{array}$ & $\begin{array}{l}4.59 \\
4.34\end{array}$ & 0.031 \\
\hline $\begin{array}{l}\text { Use the knowledge of one's own role and } \\
\text { those of other professions to appropriately } \\
\text { assess and address the health care needs } \\
\text { of patients and populations served. }\end{array}$ & $\begin{array}{l}2014 \\
2017\end{array}$ & $\begin{array}{c}0 \\
3 \%\end{array}$ & $\begin{array}{l}1 \% \\
6 \%\end{array}$ & $\begin{array}{l}10 \% \\
10 \%\end{array}$ & $\begin{array}{l}22 \% \\
22 \%\end{array}$ & $\begin{array}{l}67 \% \\
67 \%\end{array}$ & $\begin{array}{l}4.56 \\
4.24\end{array}$ & 0.009 \\
\hline $\begin{array}{l}\text { Communicate with patients, families, } \\
\text { communities, and other health professionals } \\
\text { in a responsive and responsible manner that } \\
\text { supports a team approach to the maintenance } \\
\text { of health and tx of disease. }\end{array}$ & $\begin{array}{l}2014 \\
2017\end{array}$ & $\begin{array}{c}0 \\
4 \%\end{array}$ & $\begin{array}{l}1 \% \\
4 \%\end{array}$ & $\begin{array}{l}7 \% \\
9 \%\end{array}$ & $\begin{array}{l}17 \% \\
21 \%\end{array}$ & $\begin{array}{l}75 \% \\
62 \%\end{array}$ & $\begin{array}{l}4.65 \\
4.32\end{array}$ & 0.007 \\
\hline $\begin{array}{l}\text { Apply relationship-building values and } \\
\text { principles of team dynamics to perform } \\
\text { effectively in team roles to plan and deliver } \\
\text { patient-/population-centered care that is safe, } \\
\text { timely, efficient, effective, and equitable. }\end{array}$ & $\begin{array}{l}2014 \\
2017\end{array}$ & $\begin{array}{c}0 \\
4 \%\end{array}$ & $\begin{array}{l}2 \% \\
5 \%\end{array}$ & $\begin{array}{l}8 \% \\
10 \%\end{array}$ & $\begin{array}{l}22 \% \\
22 \%\end{array}$ & $\begin{array}{l}68 \% \\
60 \%\end{array}$ & $\begin{array}{l}4.55 \\
4.26\end{array}$ & 0.022 \\
\hline
\end{tabular}


Table 6. Program directors' responses in 2017 concerning introduction of interprofessional education (IPE) in Standard 2-15, by percentage of total respondents $(\mathrm{N}=117)$

\begin{tabular}{|c|c|c|c|c|c|c|}
\hline Item & 1 & 2 & 3 & 4 & 5 & $\begin{array}{l}\text { Mean } \\
\text { SD }\end{array}$ \\
\hline We are compliant with the standard. & $3 \%$ & $9 \%$ & $26 \%$ & $26 \%$ & $36 \%$ & 3.83 \\
\hline \multicolumn{7}{|l|}{ Including IPE in Standard 2-15: } \\
\hline $\begin{array}{l}\text { Will improve profile of dental hygiene as member of health } \\
\text { care team. }\end{array}$ & $3 \%$ & $3 \%$ & $16 \%$ & $29 \%$ & $48 \%$ & $\begin{array}{l}4.17 \\
0.998\end{array}$ \\
\hline $\begin{array}{l}\text { Contributes to integrating dental hygiene into interprofessional } \\
\text { care teams. }\end{array}$ & $1 \%$ & $4 \%$ & $17 \%$ & $37 \%$ & $41 \%$ & $\begin{array}{l}4.12 \\
0.906\end{array}$ \\
\hline Will improve patient care. & $2 \%$ & $7 \%$ & $24 \%$ & $30 \%$ & $37 \%$ & $\begin{array}{c}3.94 \\
1.024\end{array}$ \\
\hline Improves dental hygiene education efforts. & $2 \%$ & $9 \%$ & $25 \%$ & $32 \%$ & $32 \%$ & $\begin{array}{c}3.84 \\
1.031\end{array}$ \\
\hline Is a timely action. & $3 \%$ & $6 \%$ & $26 \%$ & $35 \%$ & $30 \%$ & $\begin{array}{l}3.83 \\
1.012\end{array}$ \\
\hline Challenges our program to revise the curriculum. & $2 \%$ & $9 \%$ & $27 \%$ & $38 \%$ & $22 \%$ & $\begin{array}{l}3.68 \\
1.031\end{array}$ \\
\hline Will require additional resources for our program. & $3 \%$ & $16 \%$ & $33 \%$ & $30 \%$ & $18 \%$ & $\begin{array}{l}3.44 \\
1.066\end{array}$ \\
\hline Will be a burden because of already existing curriculum overload. & $10 \%$ & $20 \%$ & $23 \%$ & $30 \%$ & $17 \%$ & $\begin{array}{l}3.26 \\
1.236\end{array}$ \\
\hline Is an unnecessary action. & $31 \%$ & $32 \%$ & $24 \%$ & $8 \%$ & $5 \%$ & $\begin{array}{l}2.24 \\
1.132\end{array}$ \\
\hline
\end{tabular}

Note: Response options were $1=$ disagree strongly, $2=$ disagree, $3=$ neutral, $4=$ agree, and $5=$ agree strongly.

\section{Discussion}

The new health care delivery paradigm emphasizes the importance of IPC in team-based environments that coordinate the care of patients holistically. IPE is therefore a necessary means to ensure that future dental hygienists can successfully function in this team role. Such educational efforts have to go beyond single, isolated experiences to exposing students to IPE and IPC longitudinally over the course of their studies. ${ }^{6,11,22}$ The explicit IPE CODA standard mandates that program directors ensure their graduates are competent in engaging in IPC. ${ }^{20}$ This study sought to compare IPE efforts before and after implementation of CODA Standard 2-15.

The data collected in both years provided a solid basis for assessing the status quo and conducting a comparison of the responses. The response rates were acceptable and increased from 33\% in 2014 to about $38 \%$ in 2017 . Most program characteristics were not significantly different in these two cohorts of responses. However, program length increased from a mean of 25.80 months in 2014 to 28.02 months in 2017 ( $p=0.029)$. This finding may be due to an increase in the number of states allowing community colleges to confer a baccalaureate degree and an in- creased number of baccalaureate degree-completion programs in the last three years.

One important question for developing IPE programs is which other health professions schools or programs are available to the dental hygiene programs. There were on average fewer programs on the same campus in 2017 than in 2014 (2014 mean 5.11 vs. 2017 mean 4.31; $\mathrm{p}=0.023$ ). However, the difference in the percentage of dental hygiene programs with nursing programs on the same campus in 2014 vs. 2017 was the only statistically significant decrease in the availability of a specific program. This finding was surprising because the Institute of Medicine called for an increase in the number of baccalaureate-prepared nurses in 2011..$^{23,24}$ If a difference were expected, it would have been in the opposite direction of the actual difference between these two years.

Despite the significant decrease in mean number of available programs, the average number of actual IPE collaborations did not differ for the two years. It would be useful to compare our results with findings from other health professions concerning the frequencies with which these programs engage in IPE and with which disciplines they collaborate most often. However, while several studies have assessed students' IPE-related attitudes in dentistry, ${ }^{25-29}$ 
medicine, ${ }^{22,25,30}$ nursing, ${ }^{27,31-33}$ and pharmacy, ${ }^{26,29}$ the results of studies with program directors or deans are much less available. In 2012, Formicola et al. published a survey of dental school deans. ${ }^{15}$ Their study found that dental schools were more likely than dental hygiene programs to collaborate with medical schools, physical therapy programs, and pharmacy schools, were equally likely to have joint IPE efforts with nursing programs, but were less likely to collaborate with dental assisting programs. In 2018, a survey of residency program directors in graduate medical education reported that IPE was taking place in over $60 \%$ of those programs, with classroom-based educational efforts $(70.8 \%)$ and team-based approaches to patient care $(70.1 \%)$ being most frequently used. ${ }^{34}$

In our study, the average number of specific types of IPE interactions in 2014 and 2017 did not differ significantly. In both years, volunteer activities were the most frequently reported IPE interactions. While these types of activities are useful, it is important to consider that they may not be a required part of the core curriculum. One could therefore argue that volunteer IPE activities do not satisfy the CODA standard requirements because it is difficult or even impossible to ensure that all students participate in such voluntary activities. Additionally, the majority of the programs reported that they engaged in IPErelated basic science courses and communication training and behavioral science courses. An interesting future research question would be whether these reported basic science and behavioral science IPE activities were truly interprofessional activities, or if they merely educated students side by side in the same classroom setting. It was most encouraging to discover that close to half of the programs reported IPE-related clinical activities since engaging students in clinical IPE can provide excellent opportunities to prepare them for future IPC. Preparing graduates for IPC is defined as a core competence in IPE efforts. ${ }^{1}$ Again, future research should explore more in depth how these IPE-related clinical activities were developed and the details of their occurrence.

Another positive finding was that, on average, the dental hygiene program directors in 2017 reported that IPE was less challenging for their programs than was reported in 2014. One could argue that any curricular change may be viewed as a major challenge. However, once administrators become more familiar with the changes needed, they might be seen as less challenging. This result is therefore encouraging because it may reflect a greater level of familiarity with this content area. It could also be related to the change in Standard 2-15 that made the administrative leadership aware that it is necessary and possible to implement IPE. While the degree of perceived challenges overall decreased, the mean percentages of perceived specific barriers did not differ significantly for the two years. Schedule coordination and curriculum overload remained the top challenges to implementing IPE.

One problematic finding that deserves future attention was that, in 2017, the program directors responded less positively than in 2014 to the question of whether IPE was among the top five priorities of the dental hygiene profession in the U.S. One could possibly argue that the respondents considered that the daily professional lives of the majority of practicing dental hygienists consist of intraprofessional care efforts with dentists. However, reflecting on the argument that dental hygiene is a profession of its own, ${ }^{35,36}$ we would hope that a discussion of IPC on a national level would include a discussion of whether collaborative care by dentists and dental hygienists should be considered IPC. Aside from that point, this finding deserves attention because it could possibly undermine program directors' motivation to engage in serious IPE efforts in their programs. However, in both years, the mean responses concerning whether IPE was among the respondents' own top five priorities or among the top five priorities at their academic institutions did not differ significantly. One could have expected that the introduction of Standard 2-15 could have resulted in an increase in how much these directors prioritized IPE; however, that was not the case.

One additional noteworthy finding that deserves future attention was that the degree to which these program directors thought their graduates need to be competent in four IPE-related behaviors decreased significantly from 2014 to 2017 . This finding is surprising in two ways. First, given the new CODA Standard 2-15, one could have expected that the degree of attention to IPE-related competence may have increased from 2014 to 2017. Second, the majority of the respondents had exceptionally positive attitudes concerning introduction of this new standard and the value of IPE for their profession. The inconsistency between these positive attitudes and a decline in expected IPE-related competencies is puzzling and deserves additional attention. IPE is crucial for preparing future dental hygienists for their role in team-based IPC..$^{37}$ IPE prepares students to work with health professionals from other disciplines 
and simultaneously offers opportunities to educate these health professionals about the value of dental hygienists' contributions to overall patient health. IPE partnerships have been found to build opportunities for students to learn from each other and to build understanding, respect, and positive attitudes towards each other. ${ }^{16,38-41}$ Professional identity development is a crucial component of health professions education; however, it can result in generalizations or stereotypes about one's own profession as well as others that can support or hinder IPC..$^{37,40,42}$ One of the key ways to progress in this new paradigm is to have accreditation standards that require future practitioners to learn to treat patients collaboratively and for educators to implement the appropriate curriculum changes needed to graduate future practitioners who are competent to do so. ${ }^{2,9}$

This research had several limitations. First, while the number of respondents was sufficient to make overall comparisons between the two cohorts, subgroup analyses could not be conducted due to the small numbers of programs in certain subcategories. For example, to compare programs that grant bachelor degrees with those that grant associate degrees or to compare programs on campuses with vs. without a dental school might have been useful. However, the subgroup sizes did not allow such comparisons. Second, using open-ended responses to follow up on closed-ended questions could have provided further insights into some of these findings. For example, after indicating on a five-point scale whether IPE was among the top five priorities of the dental hygiene profession in the U.S., an open-ended question could have asked respondents to list the top five priorities of the profession and then explain why IPE/IPC was/was not on that list. Those answers could have been very informative. Future research should focus on such qualitative approaches. Third, it would have been interesting to include questions on the 2017 survey concerning whether the program directors knew the exact content of Standard 2-15, how they had heard about it, and which changes they already implemented or planned to implement in their programs as a consequence. Answers to these questions could have provided more insights into the current situation. Finally, survey research always faces the challenge of possible response bias. In this study, schools with a more pronounced interest in IPE might have been more likely to respond to the surveys in 2014 and in 2017. This possibility should result in a careful interpretation and generalization of the findings.

\section{Conclusion}

This study's findings showed that, while the average number of health professions schools on campuses with dental hygiene programs declined from 2014 to 2017, the average amount of actual cooperation did not differ between these two years. In addition, the majority of respondents reported having IPE-related volunteer activities and IPE in basic science and communication training/behavioral science classes. Overall, perceived challenges related to IPE decreased significantly from 2014 to 2017; however, evaluations of specific challenges encountered when engaging in IPE did not differ between the two years. While IPE was seen as similarly likely to be among the top priorities of the program directors and their academic institutions in both years, the degree to which IPE was among the top priorities of the dental hygiene profession in the U.S. was seen as lower in 2017 than in 2014. In addition, the degree to which these program directors believed their graduates need to be competent in IPE-related domains was lower in 2017 than in 2014, despite overall positive IPErelated attitudes. The majority of these program directors reported that their programs were compliant with Standard 2-15. However, to progress in IPE efforts, accreditation standards should require that future practitioners learn to treat patients collaboratively. This requirement would lead to curriculum changes that would result in graduating future practitioners who are competent to engage in IPC.

\section{Acknowledgments}

We want to thank Allan J. Formicola for giving us permission to use the survey developed by the ADEA Study Team on IPE and revise it for this study. We also want to thank all the program directors who took time out of their busy schedules to respond to this survey.

\section{REFERENCES}

1. Mitchell P, Wynia M, Golden R, et al. Core principles and values of effective team-based health care. Washington, DC: National Academy of Sciences, 2012.

2. Berwick DM, Nolan TW, Whittington J. The triple aim: care, health, and cost. Health Aff 2008;27(3):759-69.

3. Maxey HL, Farrell C, Gwozdek A. Exploring current and future roles of non-dental professionals: implications for dental hygiene education. J Dent Educ 2017;81(9 Suppl):eS53-8.

4. World Health Organization, Department of Human Resources for Health. Framework for action on interprofessional education and collaborative practice. Geneva: World Health Organization, 2010. 
5. Holtman MC, Frost J, Hammer DP, et al. Interprofessional professionalism: linking professionalism and interprofessional care. J Interprof Care 2011;25(5):383-5.

6. Bambini D, Emery M, DeVoest M, et al. Replicable interprofessional competency outcomes from high-volume, inter-institutional, interprofessional simulation. Pharmacy 2016;4(34):1-9.

7. Thompson BM, Bratzler DW, Fisher MJ, et al. Working together: using a unique approach to evaluate an interactive and clinic-based longitudinal interprofessional education experience with 13 professions. J Interprof Care 2016;30(6):754-61.

8. Committee on Measuring the Impact of Interprofessional Education on Collaborative Practice and Patient Outcomes, Board on Global Health. Measuring the impact of interprofessional education on collaborative practice and patient outcomes. An Institute of Medicine report. Washington, DC: National Academies Press, 2015.

9. Graffunder C, Sakurada B. Preparing health care and public health professionals for team performance: the community as a classroom. Washington, DC: National Academy of Medicine, 2016.

10. Jones ML, Boyd LD. Interdisciplinary approach to care: the role of the dental hygienist on a pediatric feeding team. J Allied Health 2012;41(4):190-7.

11. Gilligan C, Outram S, Levett-Jones T. Recommendations from recent graduates in medicine, nursing, and pharmacy on improving interprofessional education in university programs: a qualitative study. BMC Med Educ 2014;14(52):1-10.

12. Bailit HL. The oral health care delivery system in 2040: executive summary. J Dent Educ 2017;81(9):1124-9.

13. Fried JL, Maxey HL, Battani K, et al. Preparing the future dental hygiene workforce: knowledge, skills, and reform. J Dent Educ 2017;81(9 Suppl):eS45-52.

14. Theile CW. Strengths and weaknesses of the current dental hygiene educational system. J Dent Educ 2017;80(9 Suppl):eS38-44.

15. Formicola AJ, Andrieu SC, Buchanan JA, et al. Interprofessional education in U.S. and Canadian dental schools: an ADEA team study report. J Dent Educ 2012; 76(9):1250-68.

16. Lockeman KS, Appelbaum NP, Dow AW, et al. The effect of an interprofessional simulation-based education program on perceptions and stereotypes of nursing and medical students: a quasi-experimental study. Nurse Educ Today 2017;58:32-7.

17. Gurenlian JR. Interprofessional education and practice. J Dent Educ 2015;79(5 Suppl):S48-50.

18. Anderson KL, Smith BS, Maseman DC. Integration of an oral health curriculum into a physician assistant program. J Allied Health 2011;40(1):19-24.

19. Goldie MP. The future of the dental hygiene profession. Int J Dent Hyg 2012;10(1):1-2.

20. Commission on Dental Accreditation. Accreditation standards for dental hygiene education programs. 2017. At: www.ada.org/ /media/CODA/Files/dental_hygiene_ standards.pdf?la=en. Accessed 3 Oct. 2017.

21. Furgeson D, Kinney JS, Gwozdek AE, et al. Interprofessional education in U.S. dental hygiene programs: a national survey. J Dent Educ 2015;79(11):1286-94.
22. Curran VR, Sharpe D, Flynn K, et al. A longitudinal study of the effect of interprofessional education curriculum on student satisfaction and attitudes towards interprofessional teamwork and education. J Interprof Care 2010; 24(1):41-52.

23. Kutney-Lee A, Sloane DM, Aiken LH. An increase in the number of nurses with baccalaureate degrees is linked to lower rates of postsurgery mortality. Health Aff 2013;32(3):579-86.

24. Committee on an Oral Health Initiative. Advancing oral health in America. An Institute of Medicine report. Washington, DC: National Academies Press, 2011.

25. Munz SM, Kim RY, Holley TJ. Dental hygiene, dental, and medical students' OMFS/hospital dentistry-related knowledge/skills, attitudes, and behavior: an exploration. J Dent Educ 2017;81(2):149-61.

26. Wilhelm M, Poirier T, Otsuka A, Wagner S. Interprofessional ethics learning between schools of pharmacy and dental medicine. J Interprof Care 2014;28(5):478-80.

27. Czarnecki GA, Kloostra SJ, Boynton JR, Inglehart MR. Nursing and dental students' and pediatric dentistry residents' responses to experiences with interprofessional education. J Dent Educ 2014;78(9):1301-12.

28. Page LAF, Gray L, Gallagher P, et al. Untangling the web of influences on dental students' participation in interprofessional education programs. J Dent Educ 2016; 80(6):677-85.

29. Pogge EK, Hunt RJ, Patton LR, et al. A pilot study on an interprofessional course involving pharmacy and dental students in a dental clinic. Am J Pharm Educ 2018;82 (3):217-23.

30. Chua AZE, Lo DYK, Ho WHH, et al. The effectiveness of a shared conference experience in improving undergraduate medical and nursing students' attitudes towards interprofessional education in an Asian country: a before and after study. BMC Med Educ 2015;15:233.

31. Kolb S, Vasilakis T, Stein B, et al. Attitudes and preferences concerning interprofessional education of first-year students and experienced medical and nursing staff. J Interprof Care 2017;31(2):164-6.

32. Cooper D, Kim J, Duderstadt K, et al. Interprofessional oral health education improves knowledge, confidence, and practice for pediatric health care providers. Front Public Health 2017;5:209.

33. Nierenberg S, Hughes LP, Warunek M, et al. Nursing and dental students' reflections on interprofessional practice after a service-learning experience in Appalachia. J Dent Educ 2018;82(5):454-61.

34. Al Achkar M, Hanauer M, Colavecchia C, Seehusen DA. Interprofessional education in graduate medical education: survey study of residency program directors. BMC Med Educ 2018;18:11.

35. Wilkins EM, Wyche CJ, Boyd LD. The professional dental hygienist. In: Wilkins EM, ed. Clinical practice of the dental hygienist. 12th ed. Philadelphia: Lippincott Williams and Wilkins, 2017:31-46.

36. Beemsterboer PL. Ethics and professionalism. In: Beemsterboer PL, ed. Ethics and law in dental hygiene. St. Louis: Elsevier, 2017:3-13. 
37. Otsuka H, Kondo K, Ohara Y, et al. An inter- and intraprofessional education program in which dental hygiene students instruct medical students and dental students. J Dent Educ 2016;80(9):1062-70.

38. Brame JL, Mitchell SH, Wilder RS, et al. Dental and allied dental students' attitudes towards and perceptions of interprofessional education. J Dent Educ 2015; 79(6):616-25.

39. Stull CL, Blue CM. Examining the influence of professional identity formation on the attitudes of students towards interprofessional collaboration. J Interprof Care 2016;30(1):90-6.
40. Salazar FBC, Andiappan M, Radford DR, et al. Attitudes of the first cohort of student groups trained together at the University of Portsmouth Dental Academy towards dental interprofessional education. Eur J Dent Educ 2017;21(2):91-100.

41. Ateah CA, Snow W, Wener P, et al. Stereotyping as a barrier to collaboration: does interprofessional education make a difference? Nurse Educ Today 2011;31:208-13.

42. Reinders JJ, Krijnen WP, Stegenga B, et al. Perceived dentist and dental hygienist task distribution after dental and dental hygiene students' team intervention. J Dent Educ 2017;81(4):413-9. 